$12-1998$

\title{
Exploiting the Installed Base Using Cross-Merchandising and Category Destination Programs
}

Xavier Drèze

Stephen J. Hoch

University of Pennsylvania

Follow this and additional works at: https://repository.upenn.edu/marketing_papers

Part of the Advertising and Promotion Management Commons, Business Administration, Management, and Operations Commons, Business Analytics Commons, Business and Corporate Communications Commons, Business Intelligence Commons, Marketing Commons, Operations and Supply Chain Management Commons, Sales and Merchandising Commons, and the Strategic Management Policy Commons

\section{Recommended Citation}

Drèze, X., \& Hoch, S. J. (1998). Exploiting the Installed Base Using Cross-Merchandising and Category Destination Programs. International Journal of Research in Marketing, 15 (5), 459-471. http://dx.doi.org/ 10.1016/S0167-8116(98)00017-2 


\title{
Exploiting the Installed Base Using Cross-Merchandising and Category Destination Programs
}

\begin{abstract}
We investigate two ways to increase sales and customer loyalty by taking advantage of a store's installed base of current customers. We propose a classification of products into two types. Products of Type 1 are products for which consumers have a loyalty to a specific retailer and, as far as possible, always shop at that retailer for these products. The other products (Type 2) are not associated with any retailer and are bought at whichever retailer consumers happen to shop when they plan or remember to buy the product. With this in mind, we test the potential of two marketing tools to help retailers increase their share of sales of the Type 2 segment. Using a category destination program we show that one can successfully transform Type 2 into Type 1 products. Using cross-merchandising promotions, we show that one can increase the sales of Type 2 products thereby gaining a larger share of discretionary purchases than what one would receive from a straight random allocation. Both series of tests yielded significant increases in sales and profits and were deemed successful by the retailers who implemented them.
\end{abstract}

\section{Keywords}

promotion, loyalty, coupons, store traffic

\section{Disciplines}

Advertising and Promotion Management | Business | Business Administration, Management, and Operations | Business Analytics | Business and Corporate Communications | Business Intelligence | Marketing | Operations and Supply Chain Management | Sales and Merchandising | Strategic Management Policy 


\title{
Exploiting the Installed Base Using Cross-Merchandising and Category Destination Programs
}

\author{
Xavier Drèze ${ }^{*}$ \\ Stephen J. Hoch ${ }^{* *}$
}

\begin{abstract}
We investigate two ways to increase sales and customer loyalty by taking advantage of a store's installed base of current customers. We propose a classification of products into two types. Products of Type 1 are products for which consumers have a loyalty to a specific retailer and as far as possible always shop that retailer for these products. The other products (Type 2) are not associated with any retailer and are bought at whichever retailer consumers happen to shop when they plan or remember to buy the product. With this in mind, we test the potential of two marketing tools to help retailers increase their share of sales of the Type 2 segment. Using a category destination program we show that one can successfully transform Type 2 into Type 1 products. Using cross-merchandising promotions, we show that one can increase the sales of Type 2 products thereby getting a larger share of discretionary purchases than what one would receive from a straight random allocation. Both series of tests yielded significant increases in sales and profits and were deemed successful by the retailers who implemented them.
\end{abstract}

\footnotetext{
* Xavier Drèze is Assistant Professor of Marketing at the Marshall School of Business, University of Southern California.

** Stephen J. Hoch is John J. Pomerantz Professor of Marketing at the Wharton School, University of Pennsylvania.
} 


\section{Exploiting the Installed Base Using}

\section{Cross-Merchandising and Category Destination Programs}

Food retailers in the U.S. and Europe face a hostile environment characterized by slow population growth and excess retail capacity. And as alternative store formats such as mass merchant discounters (Wal-Mart), warehouse club operations (Price Club/Costco), and category killer specialists (PetSmart, Toys 'R Us) continue to carve off lines of business traditionally dominated by grocery stores, the competitive climate intensifies. The question then becomes whether and how food retailers can profitably grow their sales. The solution, if there is one, must come from better exploiting the only two strategic resources available to any retailer: (a) timely and detailed sales data; and (b) unique geographic locations.

Most retailers attempt to profitably grow sales by pursuing some combination of two generic merchandising tactics: (a) build traffic; and (b) exploit the existing installed customer base. With traffic building, the retailer attempts to grow store sales at a rapid rate while pursing cost containment. Aggressive loss leader pricing is often employed to bring consumers into the store and fuel a favorable price/value image that can be leveraged when opening new stores that steal shares from existing competition. In the U.S. the Home Depot home improvement chain currently is successfully using this formula to open new stores at a fast enough to compensate for the diminishing sales rate increases generated by their portfolio of older (> 5 years) store locations. The chain is projected to grow their sales at a $25 \% /$ annum rate through the end of the century. In recent years food retailers have begun offering costly non-grocery services such as branch banking, video rental, pharmacy, and even daycare to bring more customers into their establishments. The major rationale for Wal-Mart's supercenter concept (grocery and general 
merchandise under the same roof) is to exploit of the higher frequency of food shopping as a means for generating additional weekly traffic for the higher margin, non-grocery side of the business.

Retailers who pursue the second tactic attempt to sell more merchandise to existing customers who are already shopping their stores through a variety of merchandising ploys designed to grab more of the consumers' weekly discretionary spending. For example, many retailers have recently installed frequent shopper programs that give consumers incentives for increasing their loyalty (share of purchases) to that particular chain. In addition most Hi-Lo retailers offer a massive number (>1500 items/week) of shallow temporary price discounts that are unadvertised and therefore can only be bought by customers who have already come into the store. A comprehensive store brand program also allows retailers to exploit the installed base by inexpensively positioning their own higher margin brands next to heavily advertised traffic building national brands (Dhar and Hoch 1996a).

Although many retailing principles work in all format types, food retailing is unique in that it involves the purchase of hundreds of mundane, everyday items that must constantly be replenished. Therefore, for most consumers the frequency of food shopping is high each and every week. Given the large number of weekly shopping trips, a key to a successful retail format is repeated store visits. Every grocery purchase starts with a store visit. A retailer cannot sell products to consumers who do not visit their stores. A store visit, however, is a necessary but not sufficient condition for purchase. While visiting a store, consumers might fail to purchase a needed product for a variety of reasons. They might have habituated to purchasing the product at 
a competitor's store, find the price in the current store too high, or they might simply not remember the need to buy the product and leave the store without it.

Recent research on store choice (Coca-Cola Retailing Research Council 1994) shows that customer loyalty is low. Although typical shoppers visit supermarkets 2.2 times a week, they will visit their regular supermarkets only 0.6 times a week. This means that an average consumer shops at three to four different supermarket chains on a regular basis, a finding consistent with the work of Ehrenberg and colleagues (Kau and Ehrenberg 1984, Uncles and Ehrenberg 1990). They have documented the very high levels of penetration ( $\geq 1$ visits) achieved by competitive retailers over the period of a year. Frisbie (1980) showed that households make an average of two filler trips per week (defined as any trip where spending amounted to less than $20 \%$ of the weekly average) to food stores above and beyond their major shopping trips. Kahn and Schmittlein (1989) distinguished quick from regular trips and uncovered two shopper segments: quicks, the $34 \%$ of shoppers who on average make two quick and one regular trips per week; and regulars, the $66 \%$ of shoppers that make one regular trip per week and one quick trip every other week.

This evidence suggests that not only do households make quite a few shopping trips to food stores each week, they also frequent a large portfolio of different stores. It is a wellaccepted fact that most grocery related buying decisions are made once the consumer is already in the store. Surveys of supermarket shopping behavior (Dagnoli 1987; POPAI 1994) have found that only one third of the purchases are specifically planned before entering the store. Park, Iyer, and Smith (1989) studied buying behavior when consumers shopped at an unfamiliar store location (though the same chain) than they normally shopped. They found that the level of 
unplanned purchasing more than doubled, suggesting a preponderance of bottom-up processing of in-store merchandising activity. Bucklin and Lattin (1991) found a significant improvement in the fit of their purchase incidence, brand choice model when they explicitly recognized that consumers could visit a store and be either in a very "planned" or "opportunistic" state.

Consumers make most in-store decisions very quickly, after minimal search (Hoyer 1984) and price comparison (Dickson and Sawyer 1990). Analogous to Bucklin and Lattin's (1991) twostate planner-opportunist model, we find it worthwhile to divide shopping baskets (see Figure 1) in two classes of products: (1) products that are associated with a particular store (e.g., I buy my fresh fruit and vegetables at Dominick's and diapers at Toys 'R Us); and (2) all other products that are not associated with any particular store and are randomly bought in each store in direct proportion to the number of store visits (i.e., I buy shampoo in whichever store I am or plan to go to when I remember that I

\begin{tabular}{|l|l|}
\hline $\begin{array}{l}\text { Store A } \\
\text { Meat }\end{array}$ & $\begin{array}{l}\text { Random allocation } \\
\text { based on shopping } \\
\text { trips: }\end{array}$ \\
\cline { 1 - 1 } $\begin{array}{l}\text { Store B } \\
\text { Wine, Beer }\end{array}$ & $\begin{array}{l}\text { P(A) }=\frac{\text { \# of trip to A }}{\text { \# of trips }} \\
\text { Cereals, Laundry Detergent, } \\
\text { Store C } \\
\text { Produce }\end{array}$ \\
\cline { 1 - 1 } $\begin{array}{l}\text { Store D } \\
\text { Specialty food }\end{array}$ & \\
\cline { 1 - 1 }
\end{tabular}

Figure 1: Typical Shopping Basket need shampoo).

With this categorization in mind, retailers can try to increase their sales in two ways. They can try to convert type 2 products into type 1 products. Alternatively, they can work to increase the probability of purchase of type 2 products above the straight random allocation procedure. Ehrenberg's work applying the NBD-Direchlet model to both store and brand choice 
data suggest that in steady-state all products are of type 2 and that neither of the above tactics will work, at least in the long-run. In equilibrium, Ehrenberg may well be right, but we think of marketing as responsible for helping firms adapt to a continually evolving set of disequilibria. With this in mind we believe that the above objectives can be reached using a variety of marketing tools including advertising, price promotion, special displays, etc. In this paper, we investigate the potential of two marketing techniques to achieve these goals. First we test the effectiveness of category destination programs as a way to convert type 2 products into type 1 . Second, we test the ability of cross-merchandising techniques to alter consumers' in-store behavior and thus increase the probability that a product is bought given that the consumer is already in the store (i.e., increase a retailer's share of type 2 products).

The tests we implemented focused on general merchandise and health and beauty care products (GM/HBC). We selected these categories because they are an underdeveloped area of today's supermarkets. While supermarkets represent more than $70 \%$ of all food and dry grocery sales, they have only $20 \%$ of the GM sales. According to Nielsen, supermarkets' share of HBC went from $37 \%$ in 1986 to $34 \%$ in 1993 , while mass merchandisers enjoyed a steady growth from $18 \%$ to $26 \%$. From preliminary analysis conducted on the customer files from a U.S. east coast grocery chain, we found that about $75 \%$ of shopping trips were made without a purchase in the GM/HBC categories. Yet when consumers did actually purchase GM/HBC products, they spent an additional $\$ 5$ to $\$ 6$, increasing their check-out bill by almost $25 \%$. Hence, GM/HBC is an area of the store with much potential for increased discretionary purchases if more of the consumers who walk in the front door can be encouraged to visit this low traffic area. The 
situation is analogous to the problem faced by a small store tucked in a remote corner of a sprawling suburban mall or the top floor of a multistoried department store.

The next two sections of this paper will describe the two studies, starting with the category destination program, then going on to the cross-merchandising experiments. The last section of this paper pulls together managerial implications of the two studies.

\section{Category Destination Programs}

Category destination programs are one of many different types of continuity programs. Continuity programs such as an airline's Frequent Flyer club or Subway's "Buy 10 subs and get the $11^{\text {th }}$ free" are designed to increase loyalty by rewarding repeat purchases. They create artificial switching costs through the rewarding of cumulative purchases rather than current purchases (Banerjee and Summers 1987). The consumers who want to benefit from these programs are locking themselves into purchasing from a single source since switching to another source would imply losing the benefits accumulated through past actions.

Category destination programs and continuity programs are similar in that they both try to motivate customers to return to the same chain multiple times during a specified time period. They are different however in two aspects. First, category destination programs only reward purchases made in a specific group of related categories (e.g., a hosiery card at an upscale department store or a photo finishing rebate program). Most of the frequent shopper programs offered by food retailers provide incentives on all categories sold in the store, whereas the category destination program has a more focused identity borrowed from the categories themselves. Second, they typically have either a real or apparent membership element. These 
two characteristics are aimed at creating in the mind of the consumers a direct link between the program category and the retailer, thereby transforming the destination category from a type 2 into a type 1 category for that retailer.

\section{Program Design}

Category destination programs encourage customers to shop a given retailer for a specific group of products. These programs are particularly aimed at customers who are already shopping the store, but are only casual shoppers of the target categories. The best destination categories will be ones that exhibit higher consumer involvement, dollar expenditure, and purchase frequency because identity creation will be easier. One group of categories which meets these requirements is baby products.

Baby related products are an ideal vehicle for a category destination program for a number of reasons. First, households with newborns have annual expenditures on baby related groceries (disposable diapers, formula, baby food, wipes, and baby accessories) ranging from $\$ 1,500$ to $\$ 2,500$ (Parents Magazine, Mar. 1994). Second, a newborn increases the frequency of shopping trips in most families. Third, when asked what is most important to them in their shopping experience, new parents are unanimous: combining grocery and baby needs into a onestop shopping trip. Moreover, families with infants are less likely to have well-established shopping patterns, both because of their age and the fact that they are less likely to have resided at their address for long periods of time. Fourth, the customers who purchase the most baby care products are more affluent and educated than the general population (Supermarket Business, Dec. 1994). And fifth, the beginning of this decade has seen the highest number of births since the 
baby boom that followed World War II (Supermarket Business, Apr. 1995). All considered, the baby care market is very significant to food retailers.

With these points in mind, we designed a category destination program that would be simple enough for the retailer to administer, and yet would be rewarding enough to attract consumers.

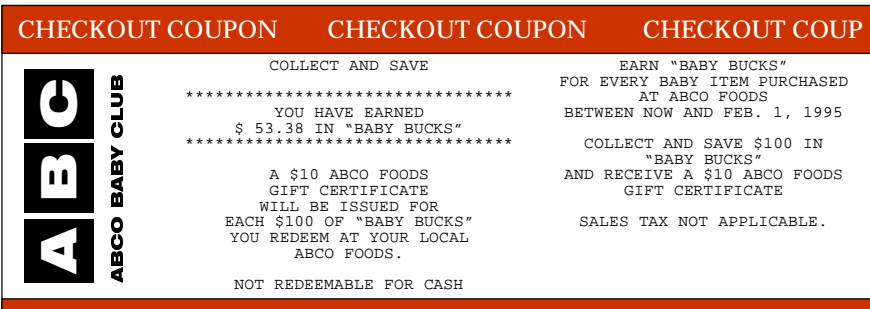

CHECKOUT COUPON CHECKOUT COUPON CHECKOUT COUP

Figure 2: Catalina Coupon

Most of the program administration work was done by the Catalina Marketing Checkout Coupon® system. Customers earned one "Baby Buck” for every dollar spent on baby related products. When a customer went through the checkout lines, the Catalina system totaled expenditures (before tax) on baby products and printed a coupon for that customer with the amount of "Baby Bucks" earned during that transaction (see Figure 2). When customers collected 100 Baby Bucks, they could redeem them for a \$10 gift certificate valid toward purchase of any merchandise in the store. This reward structure is strictly linear. Customers who double their purchases will also double the amount of "Baby Bucks" they earn. There was no need to use a more traditional convex reward structure (Klemperer and Png 1986) since our program was the only one of its kind in the test market area.

The program ran for six months (August 1, 1994 to January 31, 1995) at all 70 locations of ABCO Markets Inc. in Phoenix and Tucson, Arizona. Awareness for the program was generated by piggybacking onto existing radio and TV commercials, window banners, in-store signs, both in-aisle overhead signs and shelf talkers in front of all qualifying baby products. The 
program was also featured in $\mathrm{ABCO}$ weekly circulars with the message: "Get a free $\$ 10$ gift certificate. Join the ABCO Baby Club. See store manager for details."

\section{Hypotheses}

If a category destination program is to be successful, it must have a significant impact on the shopping pattern of customers at the retailer offering the program. The most significant impact will be at the category level with some possible spillover to the rest of the store. First and foremost, the program should increase the sales of the target categories. We will thus formulate hypothesis 1 as:

$\mathrm{H}_{1}$ : Total sales in the destination categories will increase during the test program.

The underlying motivation of the destination program is to increase store loyalty by transforming a type 2 category into a type 1 category. This should induce consumers to shop for the destination category almost exclusively at the retailer offering the program, resulting in more of their shopping trips including purchases of the target categories.

Although food retailers have a dominant share of the business in formula and baby food (>85\%), mass merchandisers have captured a significant share of the sales in the Diapers (40\%) and baby accessories (55\%) categories (Supermarket Business, Apr. 1995). Moreover, these categories represent high ticketed items. Therefore, we expect that not only will customers shop the target categories more often, they also will spend more on these categories during each shopping trip. We will then formulate hypotheses 2 and 3 as:

$\mathrm{H}_{2}$ : The number of transactions involving the destination categories will increase during the test as consumers gradually shift their baby purchases to the target retailer and newly created parents enter the market for the first time. 
$\mathrm{H}_{3}$ : The total amount of money spent on baby products on each shopping trip (conditional on purchase) will increase during the test as consumers become more familiar with the program.

Lastly, we can look at the impact of the program on store patronage and possible spillover to other categories. Since the program targeted only a very specific group of products that are of interest to only a fraction of the population, households with infants who were already shopping at $\mathrm{ABCO}$ Foods, we did not expect to see an increase in traffic due to the program. The lack of an increase in traffic means that categories which are not in the program should not see a significant spillover effect due to the program. Hence, we will formulate hypotheses 4 and 5:

$\mathrm{H}_{4}$ : $\quad$ Store traffic will be unaffected by the category destination program.

$\mathrm{H}_{5}$ : The category destination program will not affect the sales of unrelated categories.

\section{Test Results}

Sales and traffic data were collected at ABCO during the 6-month test of the Baby Club program. These data were then compared with data collected during the same time period a year previous to account for seasonality and any trends over the time series. The use of mass media promotion precluded us from setting up a group of control stores where the program was not implemented. Therefore, we have a simple pre-post quasi-experimental design. To reduce potential interpretation problems, we obtained market level information on baby categories sales from Information Resources, Inc. and used these data to control for any population growth or exogenous shocks such as a sudden craze for baby related items that could account for an increase in sales. 
In terms of baby category sales, the program yielded an overall increase of $25 \%$, with the largest increase experienced in the baby formula category with $35 \%$, followed by baby food $(18 \%)$ and diapers (17\%), with the smallest increase in baby accessories and wipes (7\%). The sales data are displayed in Figure 3 where we have plotted ABCO dollar sales versus the rest of the market in both the pre-period and during the test. The $25 \%$ increase obviously is statistically significant, $\mathrm{t}=-7.46, \mathrm{p}<.0001$, and validates $\mathrm{H}_{1}$, but more importantly it is economically significant as will become readily apparent when we examine the profit implications later. In Figure 3, sales were scaled to a common index of 100 for the pre-experimental period. This graph provides convincing evidence of the value of the program. Both $\mathrm{ABCO}$ and the rest of the market have the same intercept at the start of the test, but immediately thereafter continue to diverge throughout the period of the test. We assume that the sales effect would asymptote at some point, but there is no evidence of peaking out by the end of six months. The two slopes are quite different, 0.5 for the rest of the market compared to 1.96 for ABCO.

Given the weaknesses that accompany quasi-experiments, we ran a series of tests on the market and chain level time series to ensure that the sales increase could not be attributed to external factors. We fitted a series of models to measure market growth, seasonality and differences in growth rates between market and chain level sales. The analysis revealed no significant market growth between the pre-experimental and test periods $(t=0.88, p=0.38)$ for the total market (ABCO plus the rest of the market). However, it revealed growth within each time period attributable to a significant amount of seasonality. We fitted this seasonality using straight line OLS; it turned out to be statistically significant $(\mathrm{t}=3.46, \mathrm{p}<0.001)$. The seasonality adjustments are not significantly different for $\mathrm{ABCO}$ and for the total market area $(\mathrm{t}=0.83$, 
$\mathrm{p}=0.41$ ). Furthermore, the seasonality adjustments at the market levels are not significantly different for the two periods $(\mathrm{t}=-0.72, \mathrm{p}=0.48)$.

To validate hypotheses 2 (number of transactions) and 3 (size of transactions), we analyzed the data collected by the Catalina system. From the beginning of the test period to the end, the number of customers buying baby products each week steadily rose by $25 \%$ (see Figure 4). At the same time, store traffic rose by only $5 \%$. The per capita dollar value of each baby transaction also rose, by 7.5\% over the 6-month test period (see Figure 5). Unfortunately, we do not have transaction data from the pre-period. But taken as a whole, the data tend to support both hypotheses 2 and 3.

Hypothesis 4 and 5 however were disconfirmed. Store traffic during the test rose by $5 \%$ and total grocery sales increased by $4 \%$. These numbers are much smaller than those associated with the baby club; however, they are statistically different from zero, p's $<.05$.

\section{Cost of the Baby Club Program}

We have just shown that the category destination program had a positive impact on sales. However, to be an effective marketing tool, it must be that the rewards from the program far outstrip the costs of running it. The main cost of this program came from the redemption value of the gift certificates. (Advertising expenditures essentially are a weekly fixed cost of doing business; the in-store display materials cost less than $\$ 2500$.) Baby product sales during the promotion totaled more than $\$ 6$ million. With each Baby Buck having a $10 \notin$ face value ( $\$ 10$ gift certificate for each $\$ 100$ of purchases), the full promotional liability of the program could have run as much as $\$ 637,250$ if all consumers had redeemed $100 \%$ of their Baby Bucks. Assuming a normal category gross profit margin of 25\%, breakeven margin arithmetic (Hoch, Drèze, and 
Purk 1994) shows that sales would have had to increase $67 \%$ to cover the full $10 \%$ promotion liability associated with $100 \%$ redemption. Therefore, with full redemption the retailer would have lost money since the $25 \%$ sales gain was way
Total Baby Category Sales
$\$ 6,372,501$
Actual Baby Bucks Redeemed
for $\$ 10$ Gift Certificate
$\$ 182,650$
(29\% redemption of BB coupons)
Gift Certificates Redeemed
(80\% redemption)
$\$ 146,120$

Cost of Goods Sold on Certificate $\mathbf{\$ 1 0 9 , 5 9 0}$ (25\% Gross Margin)

Table 1: Cost of Baby Club Program below the $67 \%$ breakeven point.

In our case, however, as shown in Table 1 only $29 \%$ of the Baby Buck coupons actually were turned in, resulting in the issuing of $\$ 182,650$ worth of gift certificates. This low redemption rate is probably due to multiple factors, including some consumers who did not reach the $\$ 100$ threshold and other consumers who "spaced-out" and lost or forgot about the coupon after the fact (Hoch 1996). This low redemption rate is reminiscent of Dhar and Hoch (1996b) and further demonstrates the price discrimination advantages of coupons compared to automatically received off-the-shelf price discounts. Further reducing the promotional liability was the fact that only $80 \%$ of the gift certificates were eventually redeemed, lowering the liability from $\$ 182,650$ to $\$ 146,120$. Finally, if we take into account that the incremental cost of goods sold is $75 \%$ of the full retail price ( $100 \%$ - the $25 \%$ gross margin), the net liability ends up to be only $\$ 109,590$ (see Table 1$)$.

As a percent of sales, the cost of the promotion was $1.72 \%$. On the reward side, we have a $25 \%$ increase in Baby categories sales of $\$ 1,274,500$ (see Table 2), which leads to an incremental gross profit of $\$ 318,625$. Hence, we can compute the return on investment (Net Gain / Cost) for this promotion: $190 \%$ increase in profit. A return on investment of this 
magnitude over such a short period is quite impressive. In fact, the program was judged to be such a success by $\mathrm{ABCO}$ that it was reinstated shortly after the results were made available.

One of the reasons why the

program was successful is that it managed

to keep the costs down. In the mind of

many consumers, the program was

equivalent to $10 \%$ off all baby purchases.
Increase in Baby Sales

Due to the Program

Gross Profits on Incremental Sales

(25\% Gross Margin)

Cost of Promotion

Net Gain on Baby Categories

Table 2: Rewards from the Baby Club Program
$\$ 1,274,500$

$\$ 318,625$

$\$ 109,590$

$\$ 209,035$

In reality the program cost $\mathrm{ABCO}$ less

than $2 \%$ of sales. The reasons behind this are simple. First, consumers were rewarded only

when their expenditures on baby products reach a multiple of $\$ 100$. This means that casual and transient shoppers were not rewarded. Second, in order to benefit from the promotion, consumers needed not only to collect the baby bucks, but also redeem the gift certificates. Third, the gift certificates were good only for the purchase of new merchandise at $\mathrm{ABCO}$, hence their cost to the retailer was only 75 cents on the dollar.

\section{Taking Advantage of Existing Traffic}

With the Baby Club, we worked on increasing the sales of a category that represented a high involvement, high volume, frequent purchase for consumers in the target group. The same technique would probably not work for low involvement, long purchase cycle, or small priced items. Who would join the Shoe Polish Club? For these "smaller" categories we tried another approach: cross-merchandising. The basic idea behind cross-merchandising was to take advantage of the fact that customers are already visiting the store, and induce them to shop a part 
of the store they might not normally think about shopping. We attempted to do so by re-routing traffic from a Draw category to a Target category. A draw category is defined as a category that enjoys more foot traffic than the target category. Re-routing was accomplished by running a promotion on the target item and cross-referencing that promotion with the purchase of the draw item. For instance, we might promote bar soap (target) and tie-in the promotion with the purchase of bath tissue (draw). Next to the bath tissue product, we display a sign mentioning that there is a special deal on soap when one buys the bath tissue. The sign also would appear next to the soap products.

\section{Program Design}

We tested four levels of re-routing: Control, Traditional, In-Aisle, and Traffic Building (see Table 3). The control situation is used as a base line for the other conditions, and is a case where no re-routing takes place. The promotion on the target item is not linked to any other products. In the traditional case, the draw and the target items belong to complementary categories. This is a simple case where we are saying to the consumers: "Why don't you buy a toothbrush along with that toothpaste?" The in-aisle setup requires a bit more effort on the part of the consumers. In this case, we link two items that reside in the same aisle, but belong to different non-complementary categories. We might for instance cross-promote toothbrushes with shampoo. The last level of re-routing, traffic building, links two categories which are not only unrelated, but also are located far from each other in the store. Here, the draw item might be disposable diapers, and its associated target item toothbrushes or laundry baskets. 


\begin{tabular}{llll} 
Test & Draw & Target & Re-routing \\
\hline Control & None & Toothbrush & None \\
Traditional & Toothpaste & Toothbrush & Within Category \\
In-Aisle & Shampoo & Toothbrush & Within Aisle \\
Traffic Building & Diapers & Toothbrush & Across Store \\
\hline
\end{tabular}

Table 3: Levels of re-routing

To test our re-routing concept, we ran experiments in seven different supermarket chains. These retailers were geographically dispersed across the U.S. and Canada. Each retailer was asked to run five tests. However, for implementation reasons a total of only 29 tests were successfully carried out. When possible, each test involved 40 stores (10 for each condition) and ran for one week. The promotion was always advertised next to both the draw and the target items, and required the redemption of a coupon (see Figure 6) when purchasing the goods. We used coupons as a vehicle for our promotions for two reasons. First, coupons lower the cost of a promotion by discriminating between consumers who are aware of the promotion and those who are not (Dhar and Hoch 1996b). Second, coupons act as a constant reminder that the consumers are taking advantage of a promotion, and in the case of the cross-promotion, that they should not forget to pick the second product. We should point out, however, that these types of crossmerchandising efforts could easily be run as coupon-less promotions if the retailer has a sophisticated enough point-of-purchase system. In the control situation, the coupon could be used with the target item only (there was no draw item). In the other

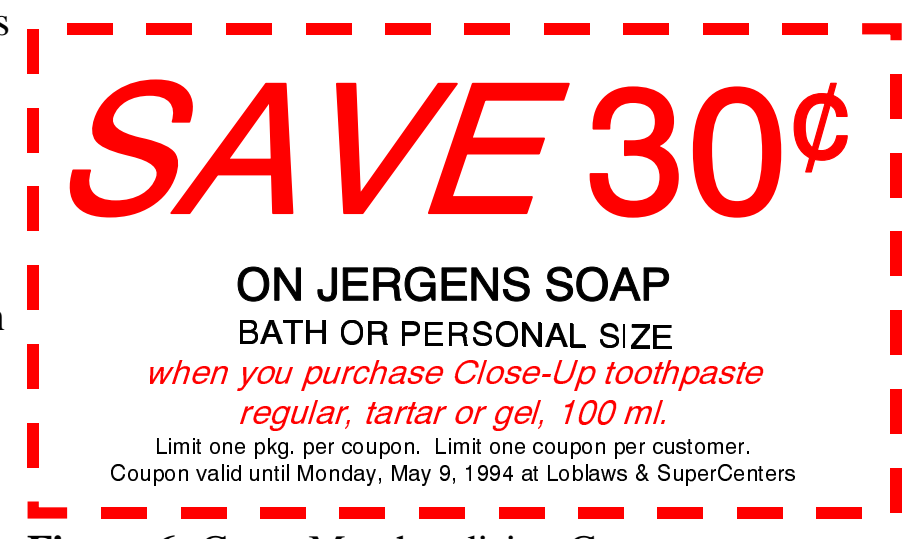

Figure 6: Cross-Merchandising Coupon 
cases, the coupon could only be used when purchasing both the draw and the target products. The draw and target items were selected from 20 different categories (see Table 4), the target item always residing in the $\mathrm{GM} / \mathrm{HBC}$ aisles.

\section{Hypotheses}

\begin{tabular}{ll}
\hline Bath Tissues & Envelopes \\
Batteries & Facial Tissues \\
Candles & Frames \& Posters \\
Crayola & Kitchenware \\
Diapers & Laundry Detergents \\
Film & Light Bulbs \\
Flour & Rubbermaid \\
Oral Care & Soap \\
Shampoo \& Cond. & Soup \\
Tennis Balls & Vitamins \\
\hline
\end{tabular}

Table 4: Cross Merchandising Categories

We expected all three test conditions to display a bigger promotion lift (the difference between promoted and regular sales) on the target item than the control condition. Furthermore, since the traffic building condition attempts to re-route customers from outside the target aisle, we expected that condition to have the largest impact on sales. We formulate hypothesis 6 and 7 as:

$\mathrm{H}_{6}: \quad$ The increase in sales due to the promotion will be greater in the test conditions than in the Control condition.

$\mathrm{H}_{7}$ : The increase in promotion lift will be largest for the traffic building condition.

The main purpose of the promotion, however, was not just to increase the sales of the target brand, but rather to develop the sales of the target category and the aisle in which the target category resides. As we have previously mentioned, it is worth five to six dollars to make a consumer peruse the GM/HBC aisles. Since the traditional and in-aisle conditions are only apparent to shoppers who are already in the GM/HBC aisles, we expect these conditions to increase category and aisle sales to a lesser extent than the traffic building condition. We still do 
expect them to increase sales because they are slowing down the shopping process and cause consumers to spend more time in the GM/HBC aisles, and actually search for products.

$\mathrm{H}_{8}$ : All three test conditions will increase the sales of the target category. The traffic building condition will increase sales the most.

$\mathrm{H}_{9}$ : All three test conditions will increase the sales of the target aisle. The traffic building condition will increase sales the most.

\section{Experimental Results}

The data collected during the tests was analyzed using a double control analysis (Drèze 1995) where sales during the test period are compared to both the control condition and to a base line period of six months prior to the test. This method allows us to control for seasonality, store size, competitive promotions and other confounding effects. Changes in sales between the test and the baseline periods were calculated using a repeated measure analysis of variance framework.

The analysis was performed at three levels: target item, target category, and rest of aisle. Change in sales of the target item is straight forward. Target category sales were calculated as total category sales minus target item sales. Rest of aisle sales refer to sales of all items residing in the same aisle as the target category, but not including the target category. If the draw category resides in the same aisle as the target category (traditional and in-aisle conditions), it is not considered as part of the rest of aisle category. The results reported here have been aggregated across all 29 experiments and are reported using the Control as the baseline condition with an index of 0 . 
In terms of changes in sales at the target item level (Hypothesis 6 and 7), the promotions run in the control stores increased sales by $80 \%$. The traffic building condition further increased the sales of the target item by $15 \%$ (see Table 5 for summary numbers and significance level). The traditional and in-aisle condition however did not significantly increase sales above the control level. We thus find support for hypothesis 7, but only partial support for hypothesis 6 .

\begin{tabular}{lccc} 
Condition & $\begin{array}{c}\text { Change in Target } \\
\text { Item Sales }^{1}\end{array}$ & $\begin{array}{c}\text { Change in Target } \\
\text { Category Sales }\end{array}$ & $\begin{array}{c}\text { Change in Rest } \\
\text { of Aisle Sales }\end{array}$ \\
\hline Traditional & $+1 \%^{\dagger 2}$ & $+7 \%^{*}$ & $+4 \%^{*}$ \\
In-Aisle & $+0 \%^{\dagger}$ & $+6 \%^{*}$ & $+2 \%^{*}$ \\
Traffic Building & $+15 \%^{* *}$ & $+10 \%^{* *}$ & $+6 \%^{* *}$ \\
\hline
\end{tabular}

Table 5: Changes in Sales due to the tests

As expected, all three test conditions had a positive impact on target category sales. The increase was the largest for the traffic building condition (10\%). The traditional and in-aisle condition increased sales by roughly the same amount with $7 \%$ and $6 \%$ increase respectively. The rest of the target aisle's sales followed a similar pattern with an increase in sales of $6 \%$ in the traffic building condition, and $4 \%$ and $2 \%$ for the traditional and in-aisle conditions. We thus find validation for hypotheses 8 and 9 .

\section{Coupon Redemption}

Even though coupons were only a tool in our experiments, we can learn from the redemption pattern across the various test conditions (see Figure 7). We will define redemption rate as the percentage of target

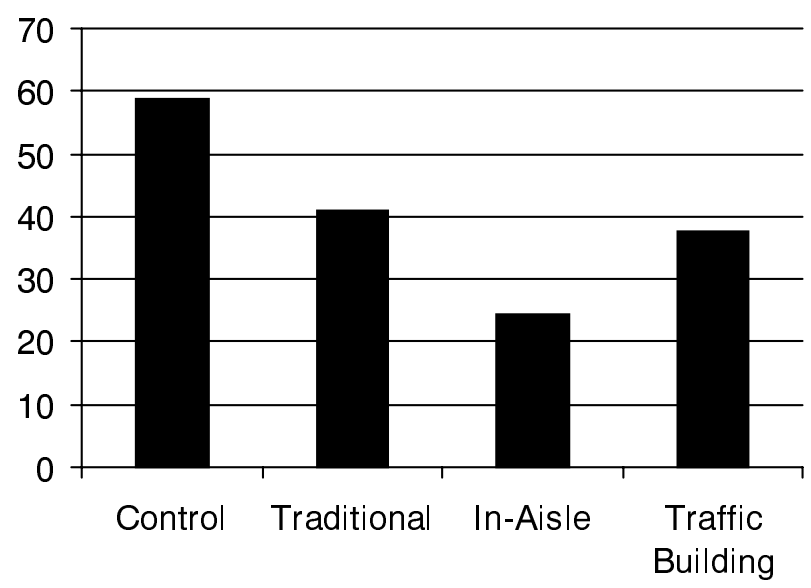

Figure 7: Coupon Redemption 
sales that were bought with a coupon. As we can see, the redemption rates are lower for the test conditions (average 34\%) than for the Control (59\%). This can be readily explained by the fact that the Control transaction was easier to complete than the Test ones (one product to purchase versus two). One can also observe that the traffic building redemption rate is almost identical to the traditional one (38\% vs. $41 \%)$. This is a good sign for our experiments. It means that consumers are capable of successfully carrying through a transaction that involves two unrelated categories located halfway across the store from each other.

\section{Conclusion}

We started this paper by highlighting some of the challenges facing traditional food retailers. Customer loyalty in the nineties is low. Customers shop often, but they shop a wide variety of outlets without clear preferences for one or another. Rather than being discouraged by these facts, we saw in them an opportunity to experiment with some relatively novel merchandising tactics: cross-promotions and category destination programs. As a prelude to our experiments, we classified products into two types (recall Figure 1). Type 1 products are products that consumers always purchase at the same store. Type 2 products for which consumers do not have a preferred store, and buy them at whichever store they are when they intend or remember to purchase the product. With this dichotomy in mind, we tested two possible strategies to increase customer loyalty and category sales. The first possible strategy is to transform a Type 2 product into a Type 1 . This was tested using a category destination program (Baby Club). The second strategy is to increase the probability of purchase of a Type 2 
product above a simple random allocation. This second strategy was tested using crossmerchandising promotions.

Both tests proved to be very successful. The Baby Club increased sales in the baby related categories by $25 \%$. It also benefitted other parts of the store by increasing foot traffic by $5 \%$ and grocery sales by $4 \%$. The program was so popular that it was reinstated shortly after the test was concluded. The cross-merchandising tests showed that it is possible to take advantage of foot traffic and increase sales in under-visited areas of a store. This was done by re-routing customers from high traffic categories to low traffic ones through the linking of the two categories in a joint promotion. Our tests showed that the two categories need not be complementary or even related. In fact the best results were obtained when the two categories were unrelated because in this case the unrelated draw category generated the most traffic due to its high frequency and volume of purchase.

With these two techniques, we were able to transform the shopping basket of Figure 1 into the one of Figure 8. In this new shopping basket, the baby related products are bought from a single retailer $(\mathrm{A}$, the one offering the Baby Club program). At the same time, using cross promotions, the retailer is also capable of increasing the probability that customers make their discretionary purchases in the GM/HBC aisles in his stores. One can look at these two techniques as being to different forms of

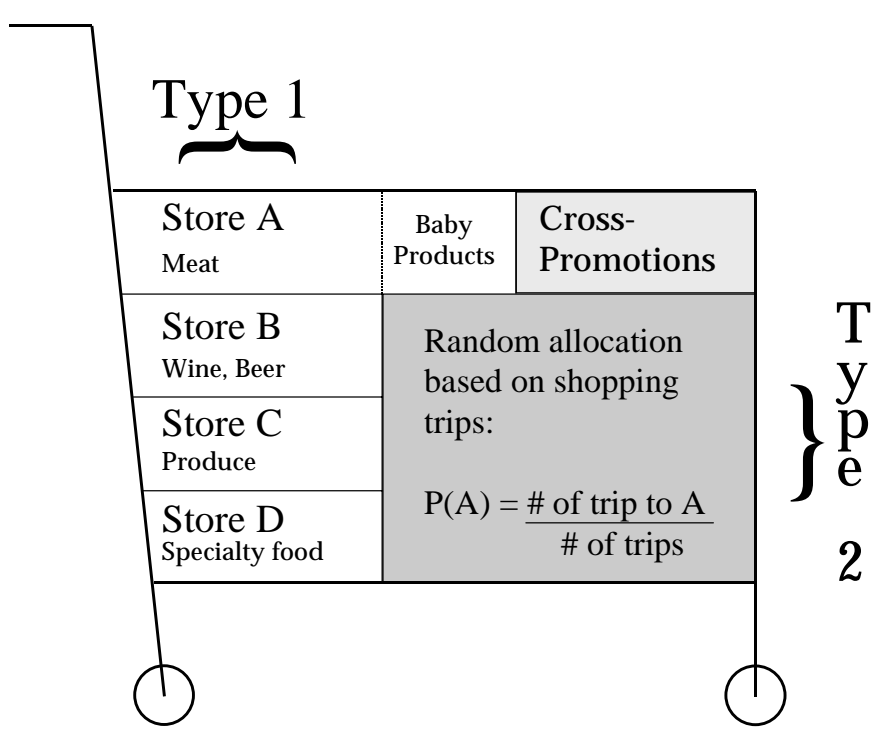

Figure 8: New Shopping Basket 
product bundling. The cross promotions we have used are a clear example of mixed-leader bundling (Guiltinan 1987) where one receives a special bonus on the target item when one buys the draw item too. The baby Club can be viewed as a special case of mixed-joint bundle where one receives the incentives after buying a bundle of baby related products that amount to $\$ 100$. This is a special case of bundling in two respects. First, the content of the bundle is determined by the consumer and not the retailer. Second, the bundling can take place over multiple store visits.

Of course we might wonder what would happen if everybody had a Baby Club and everybody used cross-merchandising? One could argue that if everybody were to have the same category destination program and used the same cross-promotions, we would be back to square one, with no increase in sales, but sharp increases in costs. The evidence provided by the literature on switching costs (see Klemperer, 1995, for a comprehensive review) suggests, however, that the situation would not be this dramatic. Indeed, in a market where competitors are capable of inducing switching costs (e.g., with the "Baby Club"), they are able to raise their prices due to a decrease in competition between firms, and a decrease in price sensitivity on the consumer side. This increase in prices compensates for the decrease in revenue generated by the coupons.

We see the retailing world as a dynamic environment where retailers have to continuously re-evaluate their strategies, testing new ideas, eliminating worn out strategies, and revising those that work in the face of competitive reaction. Indeed, to build customer loyalty and maintain a sufficient customer base, retailers constantly have to re-invent themselves and devise better ways to fulfill consumers' needs as a means of extracting consumer surplus. They have to differentiate 
themselves from their competition in order to give their customers a reason to come back at their stores.

\section{Acknowledgments}

The authors would like to thank the American Greetings Corporation for funding this research. They would also like to thank the retail members of the American Greeting Research Council II for allowing them to run experiments in their stores, IRI for providing additional market level data, and Mary Purk for valuable insights and project management.

\section{References}

Bucklin, Randolph E., and James M. Lattin (1991), “ A Two-state Model of Purchase Incidence and Brand Choice," Marketing Science, 10 (Winter), pp. 24-39.

Coca-Cola Retailing Research Council (1994), "Measured Marketing: A Tool to Shape Food Store Strategy."

Banerjee, A., and L. H. Summers (1987), “On Frequent Flyer Programs and other LoyaltyInducing Economic Arrangements," Harvard University working paper.

Dagnoli, J. (1987), “Impulse Governs Shoppers,” Advertising Age, October 5.

Dhar, Sanjay, and Stephen J. Hoch (1996a), "How Store Brand Penetration Varies by Retailer," Working Paper, Wharton School, University of Pennsylvania. , and (1996b), “Price Discrimination Using In-Store

Merchandising," Journal of Marketing, 60 (January), pp. 17-30.

Dickson, Peter R., and Alan G. Sawyer (1990), “The Price Knowledge and Search of 
Supermarket Shoppers," Journal of Marketing, 54 (July), pp. 42-53.

Drèze, Xavier (1995), "Scanners: Utilisation de Bases de Données a des Fins Stratégiques," Revue Française de Gestion, September-October, pp. 76-83.

Frisbie, Gil A. Jr. (1980), “Ehrenberg's Negative Binomial Model Applied to Grocery Store Trips,” Journal of Marketing Research, 17(3), pp. 385-390.

Guiltinan, Joseph P. (1987), “The Price Bundling of Services: A Normative Framework,” Journal of Marketing, 51 (April), pp. 75-85.

Hoch, Stephen J. (1996), "Segmentation When Consumers Space Out," Talk Presented at a Meeting of the Association for Consumer Research, Tucson, AZ. , Xavier Drèze, and Mary E. Purk, "EDLP, Hi-Lo, and Margin Arithmetic," Journal of Marketing, 58 (October), pp. 16-27

Hoyer, Wayne D. (1984), “An Examination of Consumer Decision Making for a Common Repeat Purchase Product,” Journal of Consumer Research, 11 (3), pp. 822-831.

Kahn, Barbara E., and David C. Schmittlein (1989), "Shopping Trip Behavior: An Empirical Investigation," Marketing Letters, 1 (1), pp. 55-69.

Kau, Ah Keng, and A. S. C. Ehrenberg (1984), "Patterns of Store Choice," Journal of Marketing Research, 21, pp. 399-409.

Klemperer, P. D. (1995), “Competition when Consumers have Switching Costs: An Overview with Applications to Industrial Organization, Macroeconomics, and International Trade,” Review of Economic Studies, 62, pp. 515-539. , and I. P. L. Png (1986), “Frequent-Flyer Miles: Marketing Device with Insidious Effects,” Los Angeles Times, Section IV.3 and 8, June 8, 1986. 
Parents Magazine (1994), "What a Baby Really Costs,” March.

Park, C. Whan, Easwar S. Iyer, and Daniel C. Smith (1989), “The Effects of Situational Factors on In-Store Grocery Shopping Behavior: The Role of Store Environment and Time Available for Shopping,” Journal of Consumer Research, 15 (March), pp. 422-433.

Point-of-Purchase Advertising Institute (1994), "POPAI Consumer Buying Habits Study: Special Report," New York: POPAI.

Uncles, M. D., and A. S. C. Ehrenberg (1990), "The Buying of Packaged Goods at US Retail Chains,” Journal of Retailing, 66 (Fall), pp. 278-296. 
Figure 3: Baby Category Sales

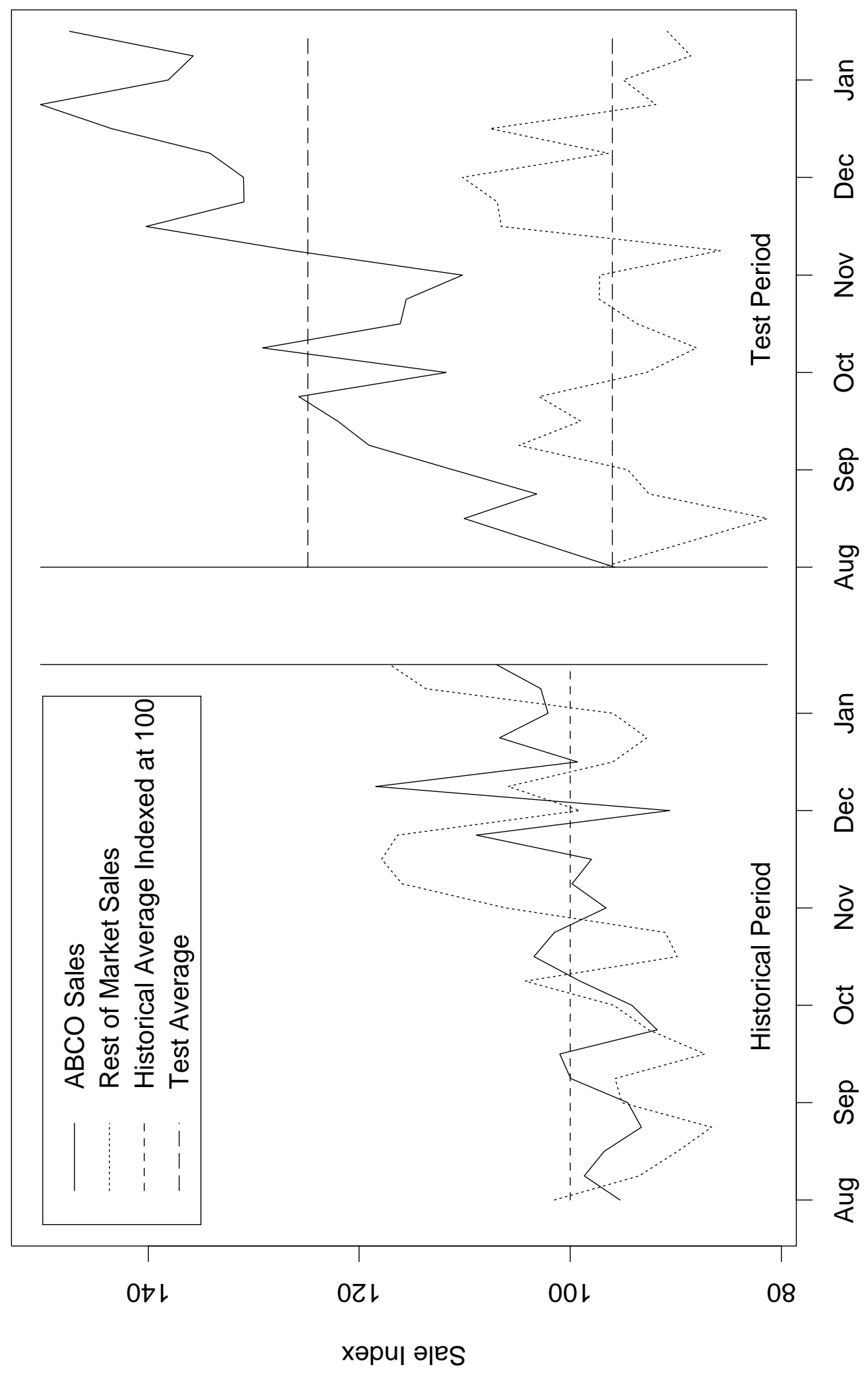


Figure 4: Number of Baby shopping trips

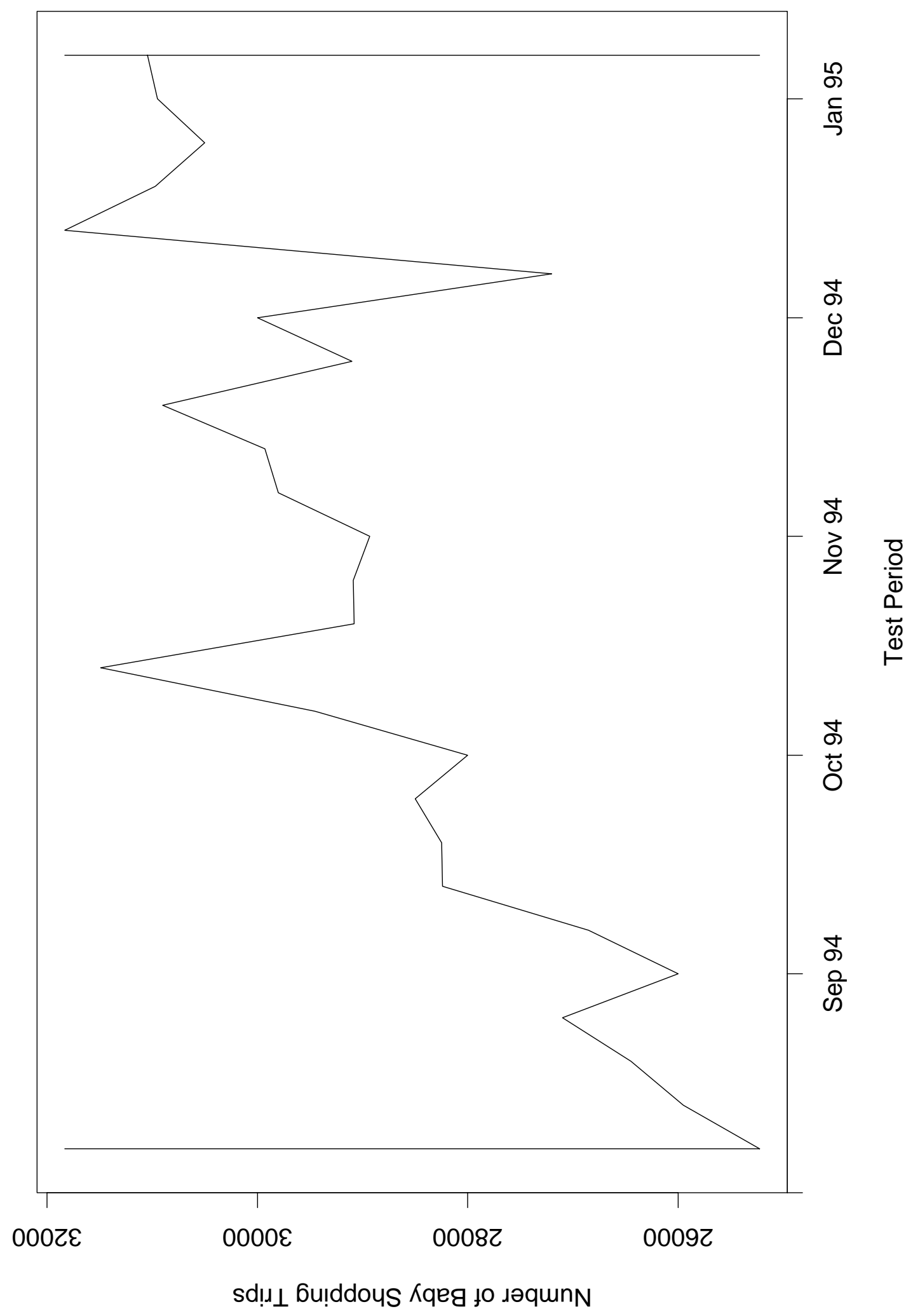


Figure 5: Amount spend on baby products per transaction

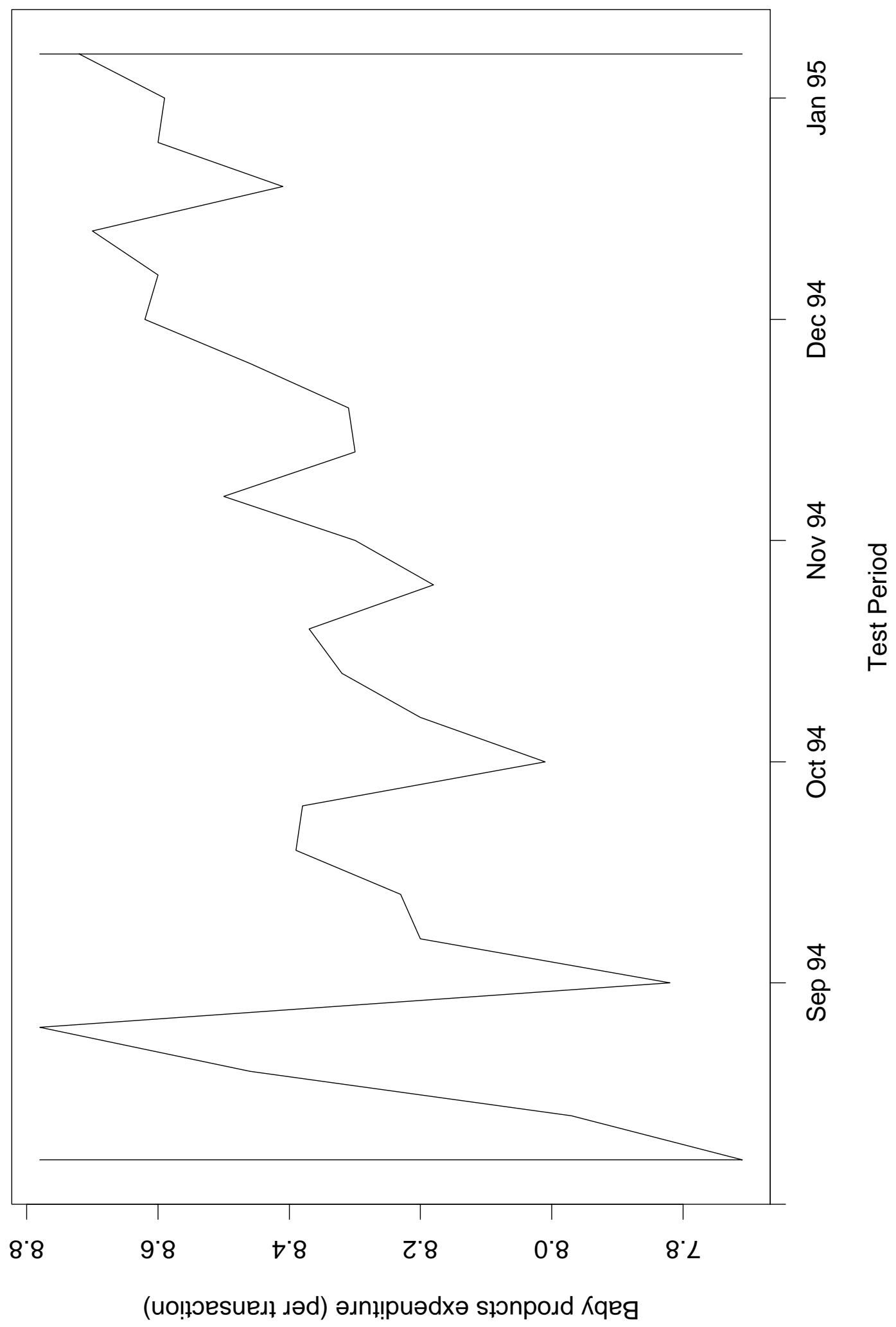


1. Indexed to Control condition

2. $\quad \dagger$ Not statistically significant

* Significant at $\mathrm{p}=0.05$ level

** Significant at $\mathrm{p}=0.01$ level 